\title{
Diagnostic and Prognostic Value of Serum Cyfra 21-1 Levels in Patients with Pancreatic Cancer
}

\author{
Jung Hoon Kim ${ }^{1}$, Young Chul Yoon ${ }^{2}$, Joon Cheol Song ${ }^{3}$, Jeong Won Jang ${ }^{3}$ and In Sook Woo ${ }^{1 *}$ \\ ${ }^{1}$ Division of Medical Oncology, Department of Internal Medicine, College of Medicine, The Catholic University of Korea, Seoul, Korea \\ ${ }^{2}$ Department of Surgery, College of Medicine, The Catholic University of Korea, Seoul, Korea \\ ${ }^{3}$ Department of Internal Medicine, College of Medicine, The Catholic University of Korea, Seoul, Korea
}

${ }^{*}$ Corresponding author: In Sook Woo M.D, Division of Medical Oncology, Department of Internal Medicine, College of Medicine, Yeouido St. Mary’s Hospital, The Catholic University of Korea, 10, 63-ro, Yeongdeungpo-gu, Seoul 07345, Korea; Tel: +8223779-1574; Fax: +822780-3132; E-mail: insookwoo@catholic.ac.kr

Received: November 22, 2018; Accepted: November 27, 2018; Published: December 05, 2018;

\begin{abstract}
Background: This study was conducted to evaluate serum cytokeratin 19-fragments (CYFRA 21-1), in addition to serum carbohydrate antigen 19-9 (CA 19-9), as a novel biomarker for the diagnosis and prognosis of pancreatic cancer.

Methods: We performed a retrospective review of medical records of the patients whose serum CYFRA 21-1 and CA 19-9 levels were estimated in a single institute from March 2011 to February 2014. The sensitivity and specificity of CYFRA 21-1 and CA 19-9 for pancreatic cancer were assessed, and the overall survival of the patients was evaluated with respect to elevation of the CYFRA 21-1 levels.

Results: Records of 57 patients diagnosed with pancreatic cancer and 110 healthy individuals (control group) were collected. CYFRA 21-1 had a sensitivity of $80.7 \%$, specificity of $80 \%$, positive predictive value of $67.6 \%$, and negative predictive value of $88.9 \%$, at a cut-off value of $1.93 \mathrm{ng} / \mathrm{ml}$ determined by a receiver operating characteristics (ROC) analysis. The area under ROC (AUC-ROC) curves of CYFRA 21-1 and CA 19-9 were 0.83 [95\% confidence interval (CI), 0.764-0.884) and 0.874 (95\% CI, 0.814-0.921), respectively without any statistically significant difference $(\mathrm{p}=0.333)$. No correlation was observed between the CYFRA 21-1 levels and the serum total bilirubin levels. For overall survival, a CYFRA 21-1 level of $\geq 5 \mathrm{ng} / \mathrm{ml}$ indicated a poor prognosis among patients with pancreatic cancers (median survival, 4.4 vs. 9.5 months, $p=0.000$ ). CYFRA 21-1 level was also found to be an independent prognostic factor in the multivariate analysis [hazard ratio, 2.277 (95\% CI, 1.137-4.559), p = 0.020].
\end{abstract}

Conclusion: CYFRA 21-1 can be a valuable biomarker for the diagnosis and prognostic prediction of pancreatic cancer.

Keywords: Cyfra 21-1, Diagnostic Performance, Pancreatic Cancer, Prognosis

\section{Introduction}

Pancreatic cancer is a fatal disease with poor response to treatment and dismal prognosis. It is a commonly occurring cancer in men and women (ranked ninth and tenth respectively) and is the fifth and the sixth leading cause of mortality, respectively, globally. It is the sole type of cancer in which the five-year relative survival rate has not shown any significant improvement in Korea from 1999 to 2015 (5.4\% to $5.7 \%$ ) [1]. Only $15-20 \%$ of patients have a resectable disease at presentation, and the initial resectability rate has also not increased in the past decades despite recent advances in the diagnostic technologies and health screening programs [2]. Therefore, there remains a huge need for an improvement in the diagnosis of pancreatic cancer in this present era.

Estimation of biomarkers from blood is an adjunctive diagnostic method for pancreatic cancer. The most commonly used and valuable biomarker for the diagnosis and monitoring of this cancer, in practice, is serum carbohydrate antigen 19-9 (CA 19-9). It is a sialylated Lewis antigen expressed in normal epithelium of pancreas, bile ducts, gallbladder, and stomach. However, because $10-15 \%$ of the total population lacks the Lewis antigen, a small proportion of patients with pancreatic cancer may not show an increase in the levels of serum CA 19-9 regardless of the tumor burden. Benign inflammation of the pancreas or biliary tract can also increase the CA 19-9 levels, leading to diagnostic inaccuracy [3]. Thus, no biomarker, superior to CA 199 , has been yet accepted.

CYFRA 21-1 is a circulating fragment of cytokeratin 19 (CK19), which is a constituent of the intermediate filament protein necessary for the structural stability of epithelial cells. CK19 is expressed in various kinds of epithelial cells but is rarely detected in the blood of healthy individuals [4]. Accordingly, serum CYFRA 21-1 levels have been widely evaluated as a potential biomarker for a variety of cancers, such as colorectal cancer [5,6], breast cancer [7], cervical cancer [8], cholangiocarcinoma [9-11], and urothelial carcinoma [12]. Presently, it is most commonly used as a tumor marker for non-small cell lung carcinoma [4,13-15]. Nakata et al. have reported that CYFRA 21-1 was effective in monitoring treatment response and detection of disease relapse in patients with breast cancer [7]. Washino et al. have shown that CYFRA 21-1 could be an indicator of advanced and highgrade urothelial carcinoma, and can be useful to monitor the disease and predict its prognosis [12]. 
However, there are very sparse data on the role of CYFRA 21-1 as a biomarker for pancreatic cancer. Boeck et al. have reported that serum CYFRA 21-1 was valuable in monitoring response to systemic chemotherapy and predict overall survival (OS) in patients with advanced pancreatic cancer [16]. Recently, Nolen et al. have evaluated the efficacy of a variety of serum biomarkers for pancreatic ductal adenocarcinoma in a large prospective cohort study of cancer screening. Their study revealed that the combination of CA 19-9, carcinoembryonic antigen (CEA), and CYFRA 21-1 could provide the highest efficacy for the detection of pancreatic ductal adenocarcinoma [17]. In the present study, we have retrospectively analyzed the diagnostic potential of serum CYFRA 21-1 for pancreatic cancer.

\section{Materials and methods}

\section{Data collection and analysis}

The medical records of the patients diagnosed with pancreatic cancer, whose serum CYFRA 21-1 and CA 19-9 were estimated at the Incheon St. Mary's Hospital, the Catholic University of Korea, College of Medicine from March 2011 to February 2014 were retrospectively collected. The patients who were diagnosed with cancer, except pancreatic cancer, were excluded. Demographic characteristics, histologic type, cancer stage, distant metastatic organs, serum CYFRA 21-1, CA 19-9, total bilirubin level, treatment modality, and clinical outcomes were analyzed by a retrospective chart review. The cancer staging was determined based on the American Joint Committee on Cancer staging system, $8^{\text {th }}$ edition. During the study period, the serum CYFRA 21-1 was uniformly measured by a two-step sandwich chemiluminescent microparticle immunoassay (Architect i2000SR, Abbott Laboratories, Ltd., Il, USA).

\section{Statistical analysis}

The comparison of groups was performed by the Kruskal-Wallis and chi-squared tests. For continuous variables, the Mann-Whitney U test was performed. The correlations among the CA 19-9, CYFRA 21-1, and serum total bilirubin levels were assessed using the Spearman correlation test. All statistical analysis was performed with SPSS version 12.0 for Windows (IBM, NY, USA), except for plotting the receiver operating characteristics (ROC) curves. The area under the ROC (AUC-ROC) curves and comparison of the ROC curves for CYFRA 21-1 and CA 19-9 were computed with MedCalc version 17.4 (MedCalc Software, Ostend, Belgium).

\section{Results}

\section{Clinicopathological characteristics of patients}

In the present study, 57 patients were diagnosed with pancreatic cancer. The median age was 63 years (range $42-84$ years), and 35 (61.4\%) patients were males. For the 110 healthy individuals (control group), the median age was 55 years (range 28-82) and 58 patients $(52.7 \%)$ were males.

Of the 57 patients with pancreatic cancer, 48 (84.2\%) were histologically confirmed for ductal adenocarcinoma or adenocarcinoma otherwise. Three (5.3\%), five (8.8\%), and one
(1.8\%) patients were diagnosed with intraductal papillary mucinous neoplasm-associated carcinoma, unspecified carcinoma, and acinar cell carcinoma, respectively. At presentation, 22 patients (38.6\%) were diagnosed with pancreatic cancer without evidence of any distant metastases, while 35 patients $(61.4 \%)$ were proven to have distant metastases. The total serum bilirubin was $>2 \mathrm{mg} / \mathrm{dl}$ in $11(19.3 \%)$ patients with pancreatic cancer at the time of CYFRA 21-1 and CA 19-9 estimation. The baseline patient characteristics are enlisted in (Table 1 \& Figure 1).

Table 1. Baseline characteristics of the study population

\begin{tabular}{|c|c|c|c|}
\hline \multicolumn{2}{|c|}{ Variables } & \multirow{2}{*}{$\begin{array}{c}\begin{array}{c}\text { Pancreatic cancer } \\
(\mathbf{n}=\mathbf{5 7})\end{array} \\
64(42-84)\end{array}$} & \multirow{2}{*}{$\begin{array}{c}\begin{array}{c}\text { Control } \\
(\mathbf{n}=\mathbf{1 1 0})\end{array} \\
55(28-82)\end{array}$} \\
\hline & Median (range) & & \\
\hline & Mean (SD) & $63.7(9.3)$ & $54.6(12.3)$ \\
\hline \multirow{2}{*}{ Gender (\%) } & Male & $35(61.4)$ & $58(52.7)$ \\
\hline & Female & $22(38.6)$ & $52(47.3)$ \\
\hline \multirow{7}{*}{ Histopathology (\%) } & $\begin{array}{l}\text { Ductal } \\
\text { adenocarcinoma }\end{array}$ & $19(33.3)$ & \\
\hline & Adenocarcinoma & $29(50.9)$ & \\
\hline & $\begin{array}{l}\text { Acinar cell } \\
\text { carcinoma }\end{array}$ & $1(1.8)$ & \\
\hline & $\begin{array}{l}\text { Poorly } \\
\text { differentiated } \\
\text { carcinoma }\end{array}$ & $1(1.8)$ & \\
\hline & $\begin{array}{l}\text { Undifferentiated } \\
\text { carcinoma }\end{array}$ & $2(3.5)$ & \\
\hline & $\begin{array}{l}\text { IPMN-associated } \\
\text { carcinoma }\end{array}$ & $3(5.3)$ & \\
\hline & $\begin{array}{l}\text { Carcinoma, } \\
\text { unspecified }\end{array}$ & $2(3.5)$ & \\
\hline \multirow{5}{*}{ AJCC stage (\%) } & IA & $1(1.8)$ & \\
\hline & IIA & $3(5.3)$ & \\
\hline & IIB & $9(15.8)$ & \\
\hline & III & $9(15.8)$ & \\
\hline & IV & $35(61.4)$ & \\
\hline \multirow{2}{*}{ Disease extent (\%) } & Non-metastatic & $22(38.6)$ & \\
\hline & Metastatic & $35(61.4)$ & \\
\hline \multirow{2}{*}{$\begin{array}{l}\text { Serum total } \\
\text { bilirubin }(\mathrm{mg} / \mathrm{dl})\end{array}$} & $\leq 2$ & $46(80.7)$ & \\
\hline & $>2$ & $11(19.3)$ & \\
\hline
\end{tabular}

\section{CYFRA 21-1 and CA 19-9 levels}

The mean levels of serum CYFRA 21-1 were $13.11 \pm 26.33 \mathrm{ng} /$ $\mathrm{ml}$ and $1.64 \pm 1.27$ in the patients with pancreatic cancer and control group, respectively, showing a significant difference between the two groups ( $\mathrm{p}<0.001$ ). The mean levels of serum CA 19-9 were 5355.35 $\pm 13625.22 \mathrm{ng} / \mathrm{ml}$ and $40.39 \pm 219.96$ in the patients with pancreatic 
cancer and control group, respectively, showing a significant difference between the two groups $(\mathrm{p}<0.001)$. In 22 patients with non-metastatic pancreatic cancer, the mean CYFRA 21-1 and CA 19-9 levels were $2.87 \pm 2.71 \mathrm{ng} / \mathrm{ml}$ and $582.19 \pm 854.49 \mathrm{U} / \mathrm{ml}$, respectively. Both the markers were significantly higher in the patients with non-metastatic pancreatic cancer than in the control group $(\mathrm{p}=0.002$ and $\mathrm{p}<0.001$, respectively) (Table 2 and Figure $2 \& 3$ ).

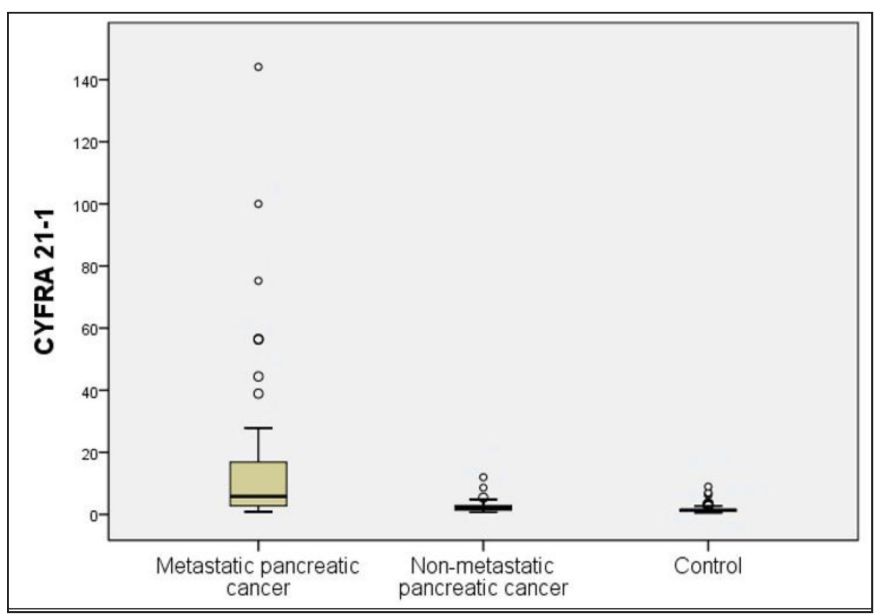

Figure 1. Distribution of serum CYFRA 21-1 levels in the patients with advanced pancreatic cancer, localized pancreatic cancer, and the control group

Table 2. Serum CYFRA 21-1 and CA 19-9 levels

\begin{tabular}{|c|c|c|c|}
\hline Biomarker (n) & $\begin{array}{c}\text { Metastatic } \\
\text { pancreatic cancer } \\
(\mathbf{n}=\mathbf{3 5})\end{array}$ & $\begin{array}{c}\text { Non-metastatic } \\
\text { Pancreatic cancer } \\
(\mathbf{n}=\mathbf{2 2})\end{array}$ & $\begin{array}{c}\text { Control } \\
(\mathbf{n}=\mathbf{1 1 0})\end{array}$ \\
\hline $\begin{array}{c}\text { CYFRA 21-1 } \\
(\mathrm{ng} / \mathrm{ml}) \\
(\mathrm{mean} \pm \mathrm{SD})\end{array}$ & $19.35 \pm 32.05$ & $2.87 \pm 2.71$ & $1.64 \pm 1.27$ \\
\hline $\begin{array}{c}\text { CA } 19-9(\mathrm{U} / \mathrm{ml}) \\
(\mathrm{mean} \pm \mathrm{SD})\end{array}$ & $8355.63 \pm 16772.34$ & $582.19 \pm 854.49$ & $40.39 \pm 219.96$ \\
\hline SD, standard deviation & & \\
\hline
\end{tabular}

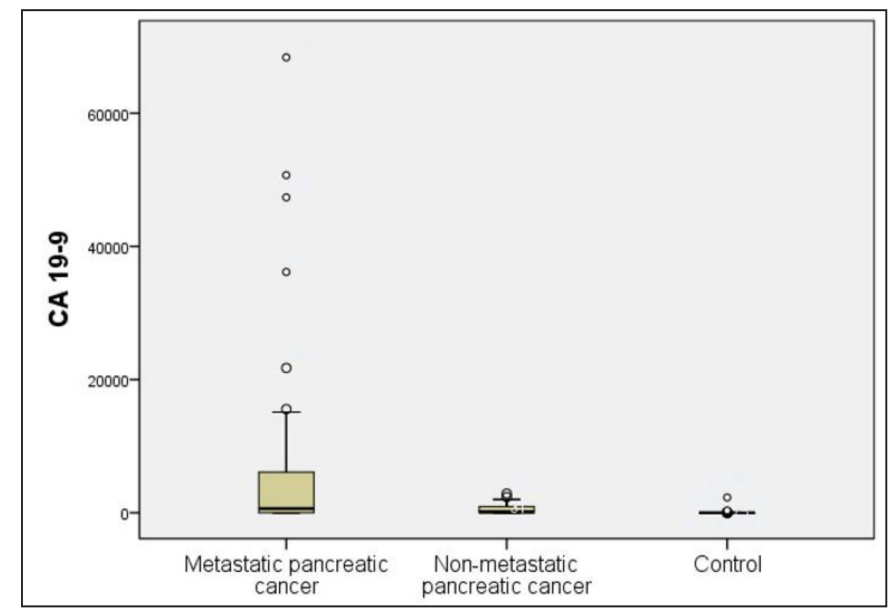

Figure 2. Distribution of serum CA 19-9 levels in the patients with advanced pancreatic cancer, localized pancreatic cancer, and the control group

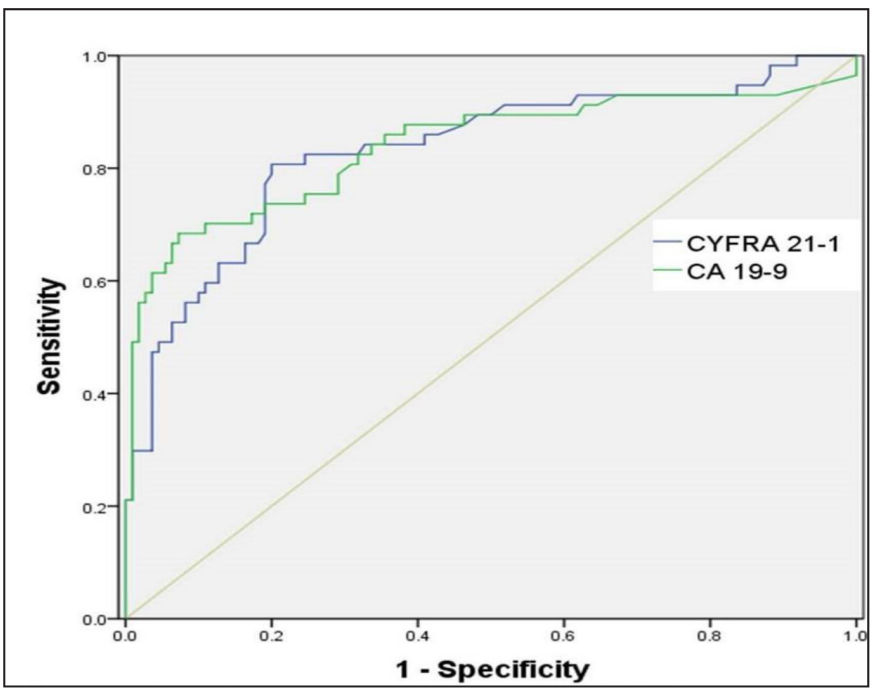

Figure 3. Receiver operating characteristic (ROC) curves for CYFRA 21-1 and CA 19-9

Determination of the cut-off value, sensitivity, specificity, and predictive value of CYFRA 21-1 using ROC curve analysis

CYFRA 21-1 was elevated in 46 patients with pancreatic cancer, and 22 patients without malignancy, with a cut-off value of $1.93 \mathrm{ng} /$ $\mathrm{ml}$. The sensitivity, specificity, positive predictive value, and negative predictive value were $80.7 \%, 80 \%, 67.6 \%$, and $88.9 \%$, respectively. The sensitivity, specificity, positive predictive value, and negative predictive value of CA $19-9$ were $75.4 \%, 84.5 \%, 71.7 \%$, and $84.5 \%$, respectively, with a cut-off value of $35 \mathrm{U} / \mathrm{ml}$. No significant difference was observed in the sensitivity and specificity between CYFRA 21-1 and CA 19-9.

\section{Comparison of ROC curves between CYFRA 21-1 and CA 19-9}

The AUC-ROC curves of CYFRA 21-1 and CA 19-9 were 0.83 [95\% CI, 0.764-0.884] and 0.874 (95\% CI, 0.814-0.921), respectively (Figure 3). The comparison of AUC-ROC curves between CYFRA 21-1 and CA 19-9 revealed no statistically significant difference ( $p$ $=0.333)$.

Spearman correlation coefficients among CYFRA 21-1, CA 19-9, and serum total bilirubin in patients with pancreatic cancers

There was a significant positive correlation between the CYFRA 21-1 and the CA 19-9 levels $(\mathrm{r}=0.607, \mathrm{p}<0.001)$. The CYFRA $21-1$ levels, however, did not correlate well with the serum total bilirubin levels $(r=0.057, p=0.676)$. A weak correlation between the CA 19-9 levels and the total serum bilirubin levels $(r=0.257)$ was observed, which was not statistically significant $(\mathrm{p}=0.054)$.

\section{Prognostic value of CYFRA 21-1 and CA 19-9 for patients with pancreatic cancer}

The patients with pancreatic cancers with CYFRA 21-1 levels $>5$ $\mathrm{ng} / \mathrm{ml}$ showed shorter overall survival than those with CYFRA 21-1 levels $\leq 5 \mathrm{ng} / \mathrm{ml}$ (median OS 4.4 months and 9.5 months, respectively, 
$\log$ rank $\mathrm{p}=0.000$ ) (Figure 4). A CA 19-9 level of $>300 \mathrm{U} / \mathrm{ml}$ was also an indicator of poor prognosis and corresponded to a median OS of 5.3 months. A median OS of 11.3 months was observed in patients with pancreatic cancers with CA 19-9 levels $\leq 300 \mathrm{U} / \mathrm{ml}$ (log rank $\mathrm{p}$ $=0.006$ ) (Figure 5). A multivariate analysis using Cox's regression model showed that CYFRA 21-1 was a single independent prognostic factor predicting inferior overall survival (hazard ratio $2.277,95 \% \mathrm{CI}$, $1.137-4.559, \mathrm{p}=0.020$ ).

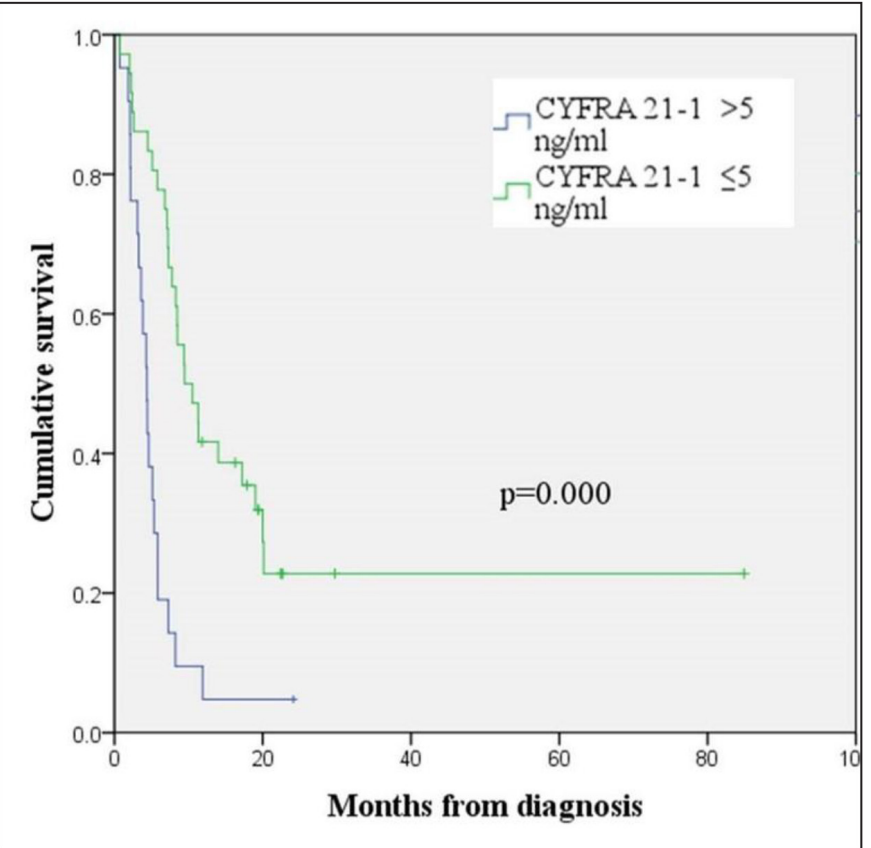

Figure 4. Kaplan-Meier curve for overall survival according to the CYFRA 21-1 level

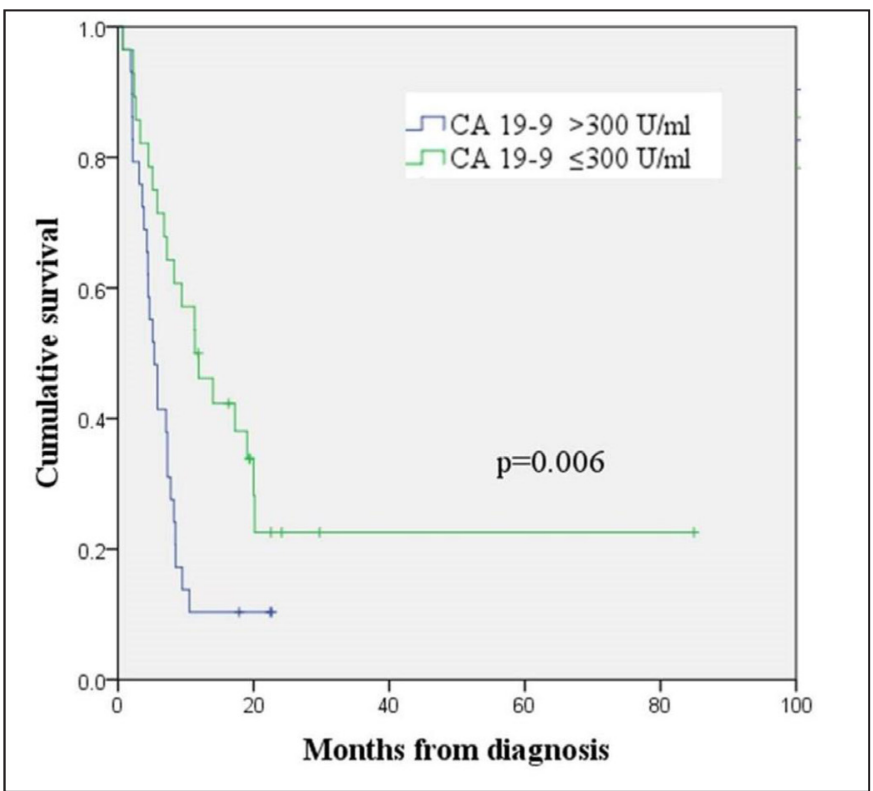

Figure 5. Kaplan-Meier curve for overall survival according to the CA 19-9 level

\section{Discussion}

The present study investigated the diagnostic and prognostic value of CYFRA 21-1 as compared to CA 19-9. Boeck et al. described the clinical utility of CYFRA 21-1 as a marker in pancreatic cancer. However, they have evaluated the response predictability to chemotherapy at a palliative setting, and its prognostic value in advanced disease [16]. Nolen et al. reported that a triple combination of CA 19-9, CEA, and CYFRA 21-1 provided the highest efficacy for screening pancreatic cancer in a prospective cohort study, and to the best of our knowledge, it is the sole study that suggested the diagnostic value of CYFRA 21-1 [17]. But their study did not explicitly provide the sensitivity, specificity, positive predictive value, and negative predictive value of CYFRA 21-1. During the course of our study, another study establishing the pre-chemotherapy CYFRA 21-1 as an independent prognostic factor in patients with advanced pancreatic cancer was published. This study, however, also did not investigate the diagnostic value of CYFRA 21-1 [18].

The median value of CYFRA 21-1 in the current study was higher than the value measured by Boeck et al. across all population subtypes $(7.5,2.6$, and $1.5 \mathrm{ng} / \mathrm{ml}$ in metastatic, recurrent, and locally advanced cancer, respectively), keeping in consideration that our study was performed in a single hospital setting [16]. The sensitivity and specificity of CYFRA 21-1 were comparable to that of CA 19-9, although it failed to prove a statistically significant superiority. The comparison of diagnostic value, as assessed by AUC-ROC curves showed no significant difference between CYFRA 21-1 and CA 199. Thus, we can hypothesize that the patients with pancreatic cancers lacking sialylated Lewis antigens may benefit from the use of CYFRA $21-1$ as a potential biomarker.

Currently, the most commonly used serum biomarker for pancreatic cancer is CA 19-9. According to the results of numerous studies, the sensitivity and specificity of CA 19-9 for pancreatic cancer vary in the range of $67-92 \%$ and $68-92 \%$, respectively [3]. Postoperative CA 19-9 is considered to be a more reliable biomarker than preoperative CA 19-9 [19-22], which is attributed to the fact that obstructive biliary stasis can also cause elevation of CA 19-9 levels $[23,24]$. Therefore, it is worthwhile to investigate another adjunctive biomarker which is not usually affected by biliary obstruction.

A variety of proteins, DNAs, and RNAs extracted from blood were assessed in various studies as additional diagnostic markers for pancreatic cancer. However, their reported diagnostic values were inconsistent to be applied in clinical practice [25-28]. Genetic molecules such as DNAs and RNAs still have low utility as biomarkers due to their reliability, practicality, and cost-effectiveness issues. CYFRA 21-1 measurement involves the detection of serum cytokeratin-19 fragment by two monoclonal antibodies. Thus, it is a relatively simple method, which can be easily utilized in routine clinical practice. Cytokeratins are known to express various subtypes in a variety of epithelial cells, and retain their molecular structures when epithelial cells are transformed during malignancy [29, 30]. Cytokeratin-19 is expressed positively in most pancreatic cancer tissues, as confirmed by immunohistochemistry [31].

This study revealed a strong positive correlation between CYFRA 21-1 and CA 19-9 levels. No correlation, however, was observed between CYFRA 21-1 and total bilirubin levels, and a weak nonsignificant correlation was observed between CA 19-9 and total 
bilirubin levels. This raises the possibility of the clinical usefulness of CYFRA 21-1 as a biomarker in pancreatic cancer.

We can hypothesize that CYFRA 21-1 may be helpful when the elevation of CA 19-9 is suspected to be confounded by obstructive biliary stasis, which is frequently present in the patients with pancreatic cancers. We, therefore, hypothesize that CYFRA 21-1 can be useful in diagnosing pancreatic cancer in patients with no elevation of CA 19-9, nevertheless, this hypothesis needs to be tested in a larger sample. Additionally, CYFRA 21-1 and CA 19-9 were found to be good prognostic indicators for pancreatic cancer. A multivariate analysis revealed that CYFRA 21-1, contrary to CA 19-9, is an independent prognostic factor for the OS in pancreatic cancer. This result is supported by previous studies by Boeck et al. [16] and Haas et al. [18].

Our study has some limitations. It is a retrospective analysis that reviewed medical records from a single institute and has heterogeneity in the study population because patients in all stages of pancreatic cancers were included. However, to the best of our knowledge, more robust results on this subject have not been published till date. In conclusion, CYFRA 21-1 can be considered as a valuable diagnostic and prognostic biomarker compared to CA 19-9 in pancreatic cancer. Larger prospective studies to verify the prognostic value of CYFRA 21-1 and CA 19-9 in pancreatic cancer are warranted.

\section{References}

1. Jung KW, Won YJ, Kong HJ, Lee ES. (2018) Cancer Statistics in Korea: Incidence, Mortality, Survival, and Prevalence in 2015. Cancer Res Treat 50: 303-316.

2. Luo J, Xiao L, Wu C, Zheng Y, et al. (2013) The incidence and survival rate of population-based patients with pancreatic cancers: Shanghai Cancer Registry 2004-2009. PLoS One. 8: 76052. [crossref]

3. Lee JK (2008) Screening and diagnosis for pancreatic cancer. Korean $J$ Gastroenterol 51: 84-88. [crossref]

4. Pujol JL, Grenier J, Daurès JP, Daver A, Pujol H, et al. (1993) Serum fragment of cytokeratin subunit 19 measured by CYFRA 21-1 immunoradiometric assay as a marker of lung cancer. Cancer Res 53: 61-66. [crossref]

5. Thomas DS, Fourkala EO, Apostolidou S, Gunu R, A Ryan, et al. (2015) Evaluation of serum CEA, CYFRA21-1, and CA125 for the early detection of colorectal cancer using longitudinal preclinical samples. Br J Cancer. 113: 268-274.

6. Lee JH (2013) Clinical Usefulness of Serum CYFRA 21-1 in Patients with Colorectal Cancer. Nucl Med Mol Imaging 47: 181-187. [crossref]

7. Nakata B, Takashima T, Ogawa Y, Ishikawa T, Hirakawa K (2004) Serum CYFRA 21-1 (cytokeratin-19 fragments) is a useful tumour marker for detecting disease relapse and assessing treatment efficacy in breast cancer. Br J Cancer 91: 873-878. [crossref]

8. Chang KH, Ryu HS, Chang SJ, Byun YJ, Lee JP (2005) Relationship between pretreatment serum SCC (squamous cell carcinoma) antigen, Cyfra 21-1 levels, and survival in squamous cell carcinoma of the uterine cervix. Cancer Res Treat. 37: 302-306. [crossref]

9. Chapman MH, Sandanayake NS, Andreola F, Dhar DK, Webster GJ, et al. (2011) Circulating CYFRA 21-1 is a Specific Diagnostic and Prognostic Biomarker in Biliary Tract Cancer. J Clin Exp Hepatol 1: 6-12. [crossref]

10. Uenishi T, Kubo S, Hirohashi K, Tanaka H, Shuto T, et al. (2003) Cytokeratin-19 fragments in serum (CYFRA 21-1) as a marker in primary liver cancer. Br J Cancer 88: 1894-1899. [crossref]

11. Uenishi T, Yamazaki O, Tanaka H, Takemura S, Yamamoto T, et al. Serum cytokeratin 19 fragment (CYFRA21-1) as a prognostic factor in intrahepatic cholangiocarcinoma. Ann Surg Oncol 15: 583-589. [crossref]

12. Washino S, Hirai M, Matsuzaki A, Kobayashi Y (2011) Clinical usefulness of CEA, CA19-9, and CYFRA 21-1 as tumor markers for urothelial bladder carcinoma. Urol Int 87: 420-428. [crossref]

13. Okamura K, Takayama K, Izumi M, Harada T, Furuyama K, et al. (2013) Diagnostic value of CEA and CYFRA 21-1 tumor markers in primary lung cancer. Lung Cancer 80: 45-49. [crossref]

14. Park SY, Lee JG, Kim J, Park Y, et al. (2013) Preoperative serum CYFRA 21-1 level as a prognostic factor in surgically treated adenocarcinoma of lung. Lung Cancer. 79: 156-160. [crossref]
15. Park HD, Jeong HS, Park JS, Lim SH (2002) Usefulness of cyfra 21-1 as a tumor marker of lung cancer. Korean J Med

16. Boeck S, Wittwer C, Heinemann V, Haas M, Kern C, et al. (2013) Cytokeratin 19-fragments (CYFRA 21-1) as a novel serum biomarker for response and survival in patients with advanced pancreatic cancer. Br J Cancer 108: 1684-1694. [crossref]

17. Nolen BM, Brand RE, Prosser D, Velikokhatnaya L, Allen PJ, et al. (2014) Prediagnostic serum biomarkers as early detection tools for pancreatic cancer in a large prospective cohort study. PLoS One 9: 94928. [crossref]

18. Haas M, Kern C, Kruger S, Michl M, Modest DP, et al. Assessing novel prognostic serum biomarkers in advanced pancreatic cancer: the role of CYFRA 21-1, serum amyloid A, haptoglobin, and 25-OH vitamin D3. Tumour Biol 36: 2631-2640. [crossref]

19. Ferrone CR, Finkelstein DM, Thayer SP, Muzikansky A, Fernandez-delCastillo C, et al. (2006) Perioperative CA19-9 levels can predict stage and survival in patients with resectable pancreatic adenocarcinoma. J Clin Oncol 24: 2897-2902. [crossref]

20. Kondo N, Murakami Y, Uemura K, Hayashidani Y, Sudo T, et al. (2010) Prognostic impact of perioperative serum CA 19-9 levels in patients with resectable pancreatic cancer. Ann Surg Oncol. 17: 2321-2329. [crossref]

21. Hata S, Sakamoto Y, Yamamoto Y, Nara S, Esaki M, et al. (2012) Prognostic impact of postoperative serum CA 19-9 levels in patients with resectable pancreatic cancer. Ann Surg Oncol 19: 636-641. [crossref]

22. Kinsella TJ, Seo Y, Willis J, Stellato TA, Siegel CT, et al. (2008) The impact of resection margin status and postoperative CA19-9 levels on survival and patterns of recurrence after postoperative high-dose radiotherapy with 5-FU-based concurrent chemotherapy for resectable pancreatic cancer. Am J Clin Oncol 31: 446-453. [crossref]

23. La Greca G, Sofia M, Lombardo R, Latteri S, Ricotta A, et al. Adjusting CA19-9 values to predict malignancy in obstructive jaundice: influence of bilirubin and C-reactive protein. World J Gastroenterol 18: 4150-4155.

24. Ong SL, Sachdeva A, Garcea G, Gravante G, Metcalfe MS, et al. (2008) Elevation of carbohydrate antigen 19.9 in benign hepatobiliary conditions and its correlation with serum bilirubin concentration. Dig Dis Sci 53: 3213-3217. [crossref]

25. Park YM, Jung HG, Son HY, Kim YS, et al. (2000) Clinical Significance of Serum p53 Protein in Patients with Pancreatic Carcinoma. Korean J Gastroenterol

26. Lee KH, Yoon WJ, Lee JK, Ryu JK, Kim YT, et al. (2005) [Quantification of plasma DNA as a tumor marker in patients with pancreatic cancer]. Korean J Gastroenterol 46: 226-232. [crossref]

27. Rogosnitzky M, Danks R (2010) Validation of blood testing for K-ras mutations in colorectal and pancreatic cancer. Anticancer Res 30: 2943-2947. [crossref]

28. Fukushima N, Walter KM, Uek T, Sato N, Matsubayashi H, et al. (2003) Diagnosing pancreatic cancer using methylation specific PCR analysis of pancreatic juice. Cancer Biol Ther 2: 78-83. [crossref]

29. Barak V, Goike H, Panaretakis KW, Einarsson R (2004) Clinical utility of cytokeratins as tumor markers. Clin Biochem 37: 529-540. [crossref]

30. Linder S (2007) Cytokeratin markers come of age. Tumour Biol 28: 189-195. [crossref]

31. Jain R, Fischer S, Serra S, Chetty R (2010) The use of Cytokeratin 19 (CK19) immunohistochemistry in lesions of the pancreas, gastrointestinal tract, and liver. Appl Immunohistochem Mol Morphol 18: 9-15. [crossref]

Citation:

Jung Hoon Kim, Young Chul Yoon, Joon Cheol Song, Jeong Won Jang, In Sook Woo (2018) Diagnostic and Prognostic Value of Serum Cyfra 21-1 Levels in Patients with Pancreatic Cancer. Internal Med Res Open J Volume 3(4): 1-5. 